\title{
SOBREVIVÊNCIA DE Xanthomonas campestris pv. viticola EM TECIDO INFECTADO DE VIDEIRA ${ }^{1}$
}

\author{
ADRIANO MÁRCIO FREIRE SILVA², ERIANNE FONSECA DE MENEZES 3 , \\ ELINEIDE BARBOSA DE SOUZA ${ }^{4}$, NATONIEL FRANKLIN DE MELO ${ }^{5}$, \\ ROSA DE LIMA RAMOS MARIANO ${ }^{6}$
}

RESUMO - Tecidos de plantas infectados constituem uma importante fonte de inóculo primário para fitobacterioses. O objetivo deste trabalho foi investigar a sobrevivência de Xanthomonas campestris pv. viticola $(\mathrm{Xcv})$, agente do cancro bacteriano da videira, em tecidos infectados na superfície do solo e durante a compostagem de restos de poda. Mudas de videira 'Festival' foram inoculadas com mutante resistente à rifampicina $X c v 2^{\text {Rif }}$ e mantidas em casa de vegetação até apresentarem alta severidade da doença. No primeiro experimento, ramos fragmentados e folhas inteiras destas plantas foram acondicionados em bolsas de malha plástica e colocados na superfície de microparcelas. No segundo experimento, ramos e folhas fragmentados foram acondicionados em bolsas plásticas e depositados no interior de pilhas de compostagem de restos de poda de videira. A sobrevivência de $X c v 2^{\text {Rif }}$ em tecidos infectados foi monitorada a intervalos de 8 e 10 dias a partir do início do primeiro e segundo experimentos, respectivamente. No primeiro experimento, foi também avaliada a decomposição de tecidos, e no segundo, as curvas de temperatura das pilhas, conteúdo de fenóis e microbiota antagonista a $X c v 2^{\text {Rif }}$. O patógeno sobreviveu em altas populações até 80 dias em tecidos infectados na superfície do solo. A compostagem eliminou $X c v 2^{\text {Rif }}$ de restos culturais em 10 dias, devido às altas temperaturas, liberação de compostos fenólicos e antagonismo microbiano. Concluindo, em tecidos infectados de videira $X c v$ sobrevive na superfície do solo por, pelo menos, 80 dias mas é eliminada pela compostagem em 10 dias.

Termos para Indexação: Cancro bacteriano da videira, restos de cultura, epidemiologia, Xanthomonas campestris pv. viticola, erradicação.

\section{SURVIVAL OF Xanthomonas campestris pv. viticola IN INFECTED TISSUES OF GRAPEVINE}

\begin{abstract}
Infected plant tissues are an important primary inoculum sources for plant bacterial diseases. This study investigated the survival of Xanthomonas campestris pv. viticola (Xcv), the agent of bacterial canker of grapevine in infected tissues on soil surface and during composting process of pruning residues. Grapevine plants cv. Festival were inoculated with a mutant resistant to rifampicin $X c v 2^{\text {Rif }}$ and maintained under greenhouse conditions until presenting high disease severity. In the first experiment, fragmented shoots and entire leaves from these plants, were placed into mesh bags and located on the surface of microplots. In the second experiment fragmented shoots and leaves were also placed into mesh bags and located inside composting piles of grapevine pruning residues. The survival of $X c v 2^{\text {Rif }}$ in infected tissue was monitored at 8 and 10 days intervals from 1 and 2 experiment setting, respectively. In the experiment 1 tissue decomposition was also evaluated and in the experiment 2, pile temperature curves, phenolyc content, and antagonism against $X c v 2^{\text {Rif }}$ were analyzed. The pathogen survived in high populations for at least 80 days in grapevine-infected tissues on soil surface. The composting process eliminated $X c v 2^{\text {Rif }}$ from crop residues in 10 days due to high temperatures, liberation of phenolyc compounds and microbial antagonism. In conclusion, Xcv survives in grapevine infected tissues on soil surface at least until 80 days but is eradicated by composting in 10 days. Index terms: Bacterial canker of grapevine, crop residues, epidemiology, Xanthomonas campestris pv. viticola, erradication.
\end{abstract}

\footnotetext{
${ }^{1}$ (Trabalho 065-12) Recebido em: 10-01-2012. Aceito para publicação em: 10-08-2012.

${ }^{2}$ Eng. Agr., Dr. Departamento de Agronomia, Universidade Federal Rural de Pernambuco, Av. Dom Manoel de Medeiros, s/n, Dois Irmãos, Recife-PE. CEP: 52171-900. E-mail: adrianomfsilva@yahoo.com.br

${ }^{3}$ Graduanda em Ciências Biológicas, Universidade de Pernambuco, Estagiária da Embrapa Semi Árido - C.P.23, Petrolina-PE. CEP 56302-970. E-mail: erianne@embrapa.cpatsa.br

${ }^{4}$ Eng. Agr., Prof. Dra. Departamento de Microbiologia, Universidade Federal Rural de Pernambuco, Av. Dom Manoel de Medeiros, s/n, Dois Irmãos, Recife, PE. CEP: 52171-900. E-mail: elineidebs@yahoo.com.br

${ }^{5}$ Biólogo, Dr. Embrapa Semi Árido, C. P. 23, Petrolina-PE. CEP 56302-970. E-mail: natoniel@embrapa.cpatsa.br

${ }^{6}$ Eng. Agr., Prof. Dra. Departamento de Agronomia, Universidade Federal Rural de Pernambuco, Av. Dom Manoel de Medeiros, s/n, Dois Irmãos, Recife-PE. CEP: 52171-900. E-mail: rrmbac@gmail.com
} 


\section{INTRODUÇÃO}

No início de 1998, o cancro bacteriano da videira (Vitis vinifera L.), causado por Xanthomonas campestris pv. viticola (Nayudu) Dye $(X c v)$, foi detectado pela primeira vez no Brasil, em parreirais do Vale do Submédio São Francisco (MALAVOLTA JÚNIOR et al., 1999). Em cultivares suscetíveis, tais como 'Red Globe' e 'Festival', o principal prejuízo é a redução da produtividade. Plantas infectadas geralmente produzem cachos com sintomas de cancro no engaço, inutilizando os frutos para a comercialização (LIMA; MOREIRA, 2002). Além dos Estados de Pernambuco, Bahia e Piauí, a doença também tem ocorrência registrada no Ceará, Roraima (MALAVOLTA JÚNIOR et al., 2008) e São Paulo (RODRIGUES NETO et al., 2011).

O conhecimento das formas de sobrevivência da bactéria fitopatogênica em condições de campo é importante para o estabelecimento de medidas eficientes de controle. Em áreas de produção de uva do Vale do Submédio São Francisco, Xcv sobrevive de um ciclo para outro em videiras, bacelos e mudas infectados; epifiticamente em videiras assintomáticas (ARAÚJO, 2001) e em hospedeiros alternativos (PEIXOTO et al., 2007).

Em tecidos infectados, difíceis de serem decompostos, a sobrevivência bacteriana é mais eficiente. Assim, práticas que acelerem a decomposição de restos culturais podem ajudar no controle da doença. Dentre as medidas recomendadas para o controle do cancro bacteriano da videira, estão a retirada e a incineração de restos de podas das áreas de cultivo (LIMA; MOREIRA, 2002). Entretanto, tal medida representa a perda de uma importante fonte orgânica de nutrientes, já que uma das principais características dos solos da região Semiárida do Brasil é o baixo conteúdo de matéria orgânica. Segundo Suárez-Estrella et al. (2007), a compostagem pode ser uma alternativa viável para o manejo de restos culturais, principalmente quando garante a destruição de possíveis fitopatógenos contidos nestes resíduos. A compostagem é um processo microbiano de biotransformação, que pode eliminar microrganismos fitopatogênicos contidos em resíduos culturais. Isto se deve, principalmente, às altas temperaturas alcançadas pelas pilhas, liberação de compostos tóxicos durante e após a fase termofílica e antagonismo microbiano em zonas de temperatura subletal (HOITINK; FAHY, 1986; ELORRIETA et al., 2003).

Apesar da importância do cancro bacteriano da videira em parreirais no Vale do Submédio São Francisco, poucas são as informações sobre as formas de sobrevivência de $X c v$, principalmente no que diz respeito à associação com tecidos infectados de videira. Este trabalho investigou a sobrevivência de $X c v$ em tecidos infectados de videira, na superfície do solo e durante a compostagem de restos de poda, com a finalidade de testar a hipótese de que restos culturais infectados deixados nos parreirais são fonte de inóculo primário de $X c v$ e que a compostagem deste material é capaz de eliminar o patógeno. Esta prática cultural proporcionará a utilização segura dos resíduos compostados, como fonte de matéria orgânica no sistema de cultivo da videira, podendo ser adicionada ao manejo integrado do cancro bacteriano no Vale do Submédio São Francisco.

\section{MATERIAL E MÉTODOS}

Foi utilizado o mutante espontâneo e estável de $X c v\left(X c v 2^{\text {Rif }}\right)$, resistente a $100 \mathrm{mg}$ de rifampicina $\mathrm{L}^{-1}$. Esse mutante apresentou crescimento em meio de cultura líquido NYD (MARIANO et al., 2005b) e patogenicidade à videira similares ao isolado selvagem $X c v 2$, pertencente à Coleção de Bactérias Fitopatogênicas do Laboratório de Fitopatologia da Embrapa Semiárido.

Eficácia de meios de cultura para os estudos de sobrevivência do isolado $X c v 2^{\text {Rif }}$

Visando a melhorar a eficácia de detecção de $X c v 2^{\text {Rif }}$ foram testadas quatro diferentes combinações de antibióticos e fungicidas a serem adicionadas ao meio de cultura NYDA (MARIANO et al., 2005b): (a) rifampicina 0,1 $\mathrm{g} \mathrm{L}^{-1}+$ ampicilina $0,1 \mathrm{~g}$ $\mathrm{L}^{-1}+$ azoxystrobim $0,16 \mathrm{~g} \mathrm{~L}^{-1}$; (b) rifampicina $0,1 \mathrm{~g}$ $\mathrm{L}^{-1}+$ azoxystrobim $0,16 \mathrm{~g} \mathrm{~L}^{-1}$; (c) rifampicina 0,1 $\mathrm{g} \mathrm{L}^{-1}+$ tiofanato metílico $0,7 \mathrm{~g} \mathrm{~L}^{-1}$; (d) rifampicina $0,1 \mathrm{~g} \mathrm{~L}^{-1}+$ ampicilina $0,1 \mathrm{~g} \mathrm{~L}^{-1}+$ tiofanato metílico $0,7 \mathrm{~g} \mathrm{~L}^{-1}$ e uma testemunha sem antibióticos ou fungicidas. Os fungicidas azoxystrobim e tiofanato metílico foram testados com base em seu espectro de atividade contra fungos habitantes de solo em ensaio preliminar (dados não apresentados). Alíquotas de $100 \mu \mathrm{L}$ de uma suspensão bacteriana de $X_{c} v 2^{\text {Rif }}$ em água destilada esterilizada (ADE) com $10^{3} \mathrm{UFC}$ $\mathrm{mL}^{-1}$ foram plaqueadas em NYDA com as diferentes combinações de antibióticos e fungicidas. As placas foram incubadas a $28^{\circ} \mathrm{C}$ por $48-72 \mathrm{~h}$, quando foi feita a contagem de colônias. A eficácia do meio de cultura foi determinada pela fórmula $\mathrm{E}(\%)=(\mathrm{UFC}$ em meio NYDA com diferentes combinações de antibióticos e fungicidas/UFC em NYDA) $\times 100$ (WYDRA et al., 2004).

O delineamento experimental foi o inteiramente casualizado, constituído por cinco tratamentos, com cinco repetições, compostas cada uma por uma 
placa de Petri.

Sobrevivência de $X c v 2^{\text {Rif }}$ em tecidos infectados de videira na superfície do solo, em microparcelas

Mudas de videira sadias da cv. Festival, com cinco pares de folhas totalmente expandidas, foram adquiridas em viveiro localizado em Petrolina - PE, e mantidas em casa de vegetação, onde folhas e ramo principal foram inoculados. As folhas foram inoculadas por fricção do limbo foliar com gaze imersa previamente em suspensão bacteriana de $X c v 2^{\text {Rif }}$ contendo $10^{8} \mathrm{UFC} \mathrm{mL}^{-1}$. O ramo principal foi inoculado nos internódios com o crescimento bacteriano pelo método da picada. Estas plantas foram submetidas à câmara úmida por três dias e mantidas em casa de vegetação até que a doença atingisse alta severidade, em média 60 dias. Após este período, as partes aéreas das mudas foram podadas e levadas para o laboratório, onde o ramo principal foi fragmentado em pedaços de aproximadamente 2,5 a 3,5 cm, enquanto as folhas foram destacadas e mantidas inteiras, com a finalidade de simular aproximadamente as condições encontradas após a poda e a passagem de roçadeira em parreirais comerciais. Da mistura destes tecidos infectados (ramos e folhas), $5 \mathrm{~g}$ foram pesados e acondicionados em bolsas de malha plástica (abertura de $2 \times 2 \mathrm{~mm}$ ) medindo $15 \times 10 \mathrm{~cm}$, as quais foram fechadas com grampeador. Cinco bolsas foram colocadas aleatoriamente na superfície de 10 microparcelas, totalizando 50 bolsas. Cada microparcela foi constituída por tonel de metal fincado ao solo (60 cm $\phi$ x $50 \mathrm{~cm}$ altura), contendo solo natural, em área experimental na Embrapa Semiárido. As microparcelas foram irrigadas por rega duas vezes por semana e, após 30 dias, foram sombreadas com tela tipo sombrite ( $50 \%$ de sombreamento), visando a simular as condições microclimáticas encontradas nos parreirais da região. Para avaliar o percentual de decomposição e as densidades populacionais de $X c v 2^{\text {Rif }}$ nos tecidos infectados de videira, a cada oito dias, durante 80 dias, cinco bolsas plásticas foram retiradas aleatoriamente das microparcelas, levadas ao laboratório, sendo seu conteúdo pesado e dele retirado $1 \mathrm{~g}$, que foi macerado com auxílio de almofariz e pistilo. As amostras foram colocadas em tubos com tampa de rosca contendo $9 \mathrm{~mL}$ de ADE, agitadas manualmente e realizadas diluições até $10^{-}$ ${ }^{4}$, plaqueando-se $100 \mu \mathrm{l}$ de cada suspensão em meio NYDA + rifampicina + ampicilina + azoxystrobin . As placas foram incubadas a $28^{\circ} \mathrm{C}$ por $48-72 \mathrm{~h}$, quando foi realizada a contagem do número de colônias por placa e calculado o número de UFC $\mathrm{g}^{-1}$ de tecido infectado. O percentual de decomposição dos tecidos infectados (DTI) foi determinado através da equação
$\mathrm{DTI}=[(\mathrm{Pi}-\mathrm{Pa}) /(\mathrm{Pi})] \times 100$, em que, $\mathrm{Pi}=$ peso inicial e $\mathrm{Pa}=$ peso na avaliação.

A temperatura, umidade relativa do ar e temperatura do solo foram monitoradas através de termoigrógrafo e termômetro de solo digital durante os 80 dias do período experimental.

Sobrevivência de $X c v 2^{\text {Rif }}$ em tecidos infectados de videira durante a compostagem de restos de poda

Análise dos tecidos de videira a serem compostados e preparação das pilhas de compostagem

Em uma área de 0,5 ha, ramos de dez videiras cv. Festival, sem sintomas da doença, foram retirados aleatoriamente da região basal, mediana e apical, antes da poda de formação. Os ramos foram triturados em forrageira e misturados, formando uma amostra composta, para a determinação da relação $\mathrm{C} / \mathrm{N}$ pelo Laboratório de Plantas e Solo da Embrapa Semiárido.

Após a realização da poda de formação, os restos de poda de cada área foram coletados e triturados em forrageira, e três pilhas de compostagem foram montadas, colocando-se de forma alternada uma camada de restos de poda e outra de esterco de caprino, na proporção de 2,5:1, em uma armação removível de madeira e tela de arame. As pilhas ficaram com dimensão de $1 \times 2 \times 0,8 \mathrm{~m}$, resultando em um volume total de $1,6 \mathrm{~m}^{3}$. A quantidade de esterco adicionado às pilhas teve como base a relação $\mathrm{C} / \mathrm{N}$ obtida. Todas as pilhas foram molhadas constantemente por meio de microaspersão.

Sobrevivência de Xcv2 ${ }^{\text {Rif }}$ durante a compostagem

Mudas de videira cv. Festival com cinco pares de folhas totalmente expandidas, inoculadas, tiveram o ramo principal e folhas fragmentados, como já descrito. Da mistura destes tecidos infectados (ramos e folhas), $10 \mathrm{~g}$ foram pesados, acondicionados em bolsas de malha plásticas (abertura de $1 \times 1$ $\mathrm{mm}$ ) medindo $20 \times 30 \mathrm{~cm}$, as quais foram fechadas com máquina de costura especializada. Três bolsas foram depositadas em cada pilha, no momento da montagem, a uma distância de $50 \mathrm{~cm}$ dos bordos e $0,40 \mathrm{~cm}$ de profundidade, sendo uma localizada no centro e duas nas extremidades.

A temperatura nas pilhas de compostagem foi monitorada a cada dois dias, durante todo o processo, em cinco pontos aleatórios, utilizando-se de termômetro de mercúrio acoplado a uma haste de metal, que permitiu sua introdução no interior das pilhas. Os primeiros revolvimentos foram feitos aos 10 e 20 dias de compostagem, quando então foi realizada a avaliação da sobrevivência de $X c v 2^{\text {Rif. }}$. Para 
isto, uma bolsa plástica foi retirada aleatoriamente de cada pilha, levadas ao laboratório e pesado $1 \mathrm{~g}$ de tecido, o qual foi macerado em almofariz com auxílio de pistilo e processado, como já descrito em sobrevivência $X_{c v} 2^{\text {Rif }}$ na superfície do solo. Após a contagem de colônias, foi calculado o número de UFC $\mathrm{g}^{-1}$ de tecido infectado.

O processo de compostagem durou 80 dias até a estabilização, durante os quais foram realizados revolvimentos a cada 10 dias. Ao final do processo, foram retiradas, de diferentes pontos de cada pilha, cinco subamostras de material compostado, as quais, misturadas em saco plástico, formaram uma amostra com aproximadamente 500 g. Esta amostra do composto foi utilizada para quantificação de compostos fenólicos totais e análise microbiológica.

Quantificação de compostos fenólicos totais

A quantificação dos compostos fenólicos totais foi realizada após fracionamento, conforme Reicher et al. (1981). Para cada fração, foram utilizados $4 \mathrm{~g}$ do composto. As leituras foram realizadas em espectrofotômetro (720nm), e os resultados foram expressos em g $100 \mathrm{~g}^{-1}$ de matéria fresca, correspondendo à soma dos fenóis dímeros, oligoméricos e poliméricos.

Detecção, quantificação e identificação de bactérias antagonistas a Xcv2 $2^{\text {Rif }}$ presentes nas pilhas de compostagem

$\mathrm{Na}$ análise bacteriológica, 1 g do composto foi adicionado a $9 \mathrm{~mL}$ de ADE em tubo de ensaio, submetido a agitação em vórtex (Phoenix AP 56) e filtrado em condições assépticas em papel de filtro esterilizado. Os filtrados foram submetidos a diluições em série até que $10^{-4}$ e $100 \mu \mathrm{L}$ de todas as diluições fossem plaqueados em triplicata em meio NYDA contendo $10^{8} \mathrm{UFC} \mathrm{mL}^{-1}$ de $X c v 2^{\text {Rif }}$. As placas foram incubadas a $28^{\circ} \mathrm{C}$, e após 48 horas, foi realizada a avaliação daquelas referentes à diluição $10^{-4}$ que possibilitou a observação de colônias isoladas, quantificação e verificação de halos de inibição. As bactérias que inibiram o crescimento do patógeno foram isoladas, purificadas, preservadas em ADE e enviadas à Embrapa Meio Ambiente, Jaguariúna-SP,para identificação.

Detecção e identificação de fungos antagonistas a Xcv2 ${ }^{\text {Rif }}$ presentes nas pilhas de compostagem

Para o isolamento dos fungos antagonistas, 25 g de composto seco foram adicionados a 250 $\mathrm{mL}$ de ADE, agitados mecanicamente durante 30 minutos, transferindo-se $10 \mathrm{~mL}$ desta suspensão para 90 mL de água, seguindo-se diluição seriada até $10^{-4}$. De cada diluição, $500 \mu \mathrm{L}$ foram plaqueados em meio de Martin (TUITE, 1969). As placas foram incubadas a $28^{\circ} \mathrm{C}$, durante 5 dias, quando as colônias fúngicas obtidas foram repicadas para meio batata-dextrose-ágar (BDA), obtendo-se as culturas puras. Estes foram cultivados em $100 \mathrm{~mL}$ de meio líquido $\mathrm{BD}$, por 10 dias, quando o crescimento foi filtrado em gaze esterilizada, centrifugado duas vezes a 10.000 rpm, por 15 minutos, filtrado em filtro Millipore ${ }^{\circledR}$ de $0,22 \mu \mathrm{m}$ e liofilizado. O filtrado liofilizado foi ressuspendido em $100 \mu \mathrm{L}$ de água, e $40 \mu \mathrm{L}$ da suspensão foram impregnados em discos de papel de filtro para teste de antibiose contra $X_{c v} 2^{\text {Rif }}$ (MARIANO et al., 2005a). Os fungos que produziram metabólitos contra $X c v$ foram preservados em ADE e enviados ao Departamento de Micologia da Universidade Federal de Pernambuco, Recife-PE, para identificação.

\section{Análises Estatísticas}

As análises de variância, o teste de Tukey para separação de médias, as análises de regressão e a correlação foram realizados com o auxílio do programa SAEG 9.1 (Sistema de Análises Estatísticas e Genéticas, Viçosa, UFV, 2007).

\section{RESULTADOS E DISCUSSÃO}

\section{Eficácia de meios de cultura para estudos de sobrevivência do isolado $X c v 2^{\text {Rif }}$ \\ Os meios NYDA + rifampicina + azoxystrobin} ou NYDA + rifampicina + ampicilina + azoxystrobin (Tabela 1) apresentaram eficácia de 68,7 e 53,1\%, respectivamente, diferindo dos demais $(\mathrm{P} \leq 0,05)$, sendo este último escolhido para resgatar $X c v 2^{\text {Rif }}$ de tecidos infectados de videira. Este meio de cultura apresentou boa eficácia, provavelmente por ter a composição do meio NYDAM (NYDA + ampicilina), comprovadamente semisseletivo para Xcv (PEIXOTO et al., 2006); foi adicionado do antibiótico rifampicina, que é utilizado para resgate do isolado mutante $X c v 2^{\text {Rif }} \mathrm{e}$ do fungicida azoxystrobim, que não inibe o patógeno e evita contaminações fúngicas.

Com relação à eficácia de meios de cultura, Wydra et al. (2004) encontraram valores de 45,6 e $188,6 \%$ para $X$. campestris pv. vignicola em meio cefazolina-celobiose-metionina, enquanto Toussaint et al. (2001) relataram índices de 5,7 a 30,7\% para $X$. campestris pv. vitians em meio maltose-verde metil. Nos dois tratamentos em que o tiofanato metílico foi adicionado, a eficácia foi muito baixa, demonstrando o efeito inibitório deste fungicida sobre $X c v 2^{\text {Rif }}$ (Tabela 1). Tal fato indica a necessidade de avaliação do efeito de fungicidas em meio de cultura elaborado para a detecção de bactérias fitopatogênicas, pois a adição de um fungicida que tenha efeito inibitório sobre a 
bactéria a ser detectada, pode levar à obtenção de dados incorretos.

Sobrevivência de $X c v 2^{\text {Rif }}$ em tecidos infectados de videira na superfície do solo em microparcelas

Nos primeiros 30 dias de experimentação, a temperatura média do ar e do solo e a umidade relativa foram de, respectivamente, $27,4 \pm 1^{\circ} \mathrm{C} ; 38,3 \pm 4,4^{\circ} \mathrm{C}$ e $49 \pm 3,4 \%$. Após o sombreamento da área experimental, foi verificada redução considerável na temperatura do ar $\left(23,2 \pm 0,95^{\circ} \mathrm{C}\right)$ e do solo $\left(28,4 \pm 1,27^{\circ} \mathrm{C}\right)$, como também um aumento na umidade relativa (61 $\pm 7,3 \%)$, condições microclimáticas mais amenas e semelhantes às que ocorrem em parreirais comerciais. Durante os 80 dias do experimento, $X c v 2^{\text {Rif }}$ foi detectada em tecidos infectados de videira, com populações variando entre $10^{4}$ a aproximadamente $10^{6} \mathrm{UFC} \mathrm{g}^{-1} \mathrm{de}$ tecido infectado (Figura 1). Infere-se que o patógeno é capaz de sobreviver em altas populações em restos de poda de videira infectados durante, pelo menos, 80 dias do ciclo da cultura, constituindo fonte de inóculo primário para plantas sadias. Nascimento et al. (2005) observaram que $X c v$ sobreviveu até 150 dias em folhas de videira herborizadas mantidas à temperatura ambiente de laboratório $\left(25 \pm 2^{\circ} \mathrm{C}\right)$. Fatmi e Schaad (2002) observaram que Clavibacter michiganensis subsp. michiganensis sobreviveu em restos de caule de tomate na superfície do solo por 314 dias, em populações variando entre $10^{6}-10^{9} \mathrm{UFC} \mathrm{g}^{-1}$ de tecido infectado. Já Barak et al. (2001) verificaram que $X$. campestris pv. vitians sobreviveu em restos culturais de alface colocados sobre o solo por até 120 dias com população de $10^{2} \mathrm{UFC} \mathrm{g}^{-1}$ de tecido infectado.

Nos primeiros 32 dias, foi observada redução mais acentuada na população de $\mathrm{X} c v 2^{\mathrm{Rif}}$ (Figura 1), que pode estar associada às condições ambientais, pois durante este período a temperatura máxima do ar e do solo foi, em média, $34,2 \pm 1,5^{\circ} \mathrm{C}$ e $46,5 \pm 6,5^{\circ} \mathrm{C}$. Jones et al. (1986), trabalhando com $X$. campestris pv. vesicatoria, concluíram que altas temperaturas do ar e do solo desfavorecem a sobrevivência bacteriana em restos de cultura. No presente estudo, dos 32 aos 64 dias, observou-se uma quase estabilização dos níveis populacionais do patógeno, provável resultado do sombreamento da área experimental, pois ocorreu redução da temperatura do ar $\left(23,2 \pm 0,95^{\circ} \mathrm{C}\right)$ e do solo $\left(28,4 \pm 1,27^{\circ} \mathrm{C}\right)$ e aumento na umidade relativa $(61 \pm 7,3 \%)$. O aumento da umidade relativa não influenciou a decomposição dos tecidos, pois foi observado durante todo experimento que a superfície do solo secava rapidamente, mesmo após o sombreamento. Outro declínio na população do patógeno foi verificado entre 64 e 80 dias, coincidindo com o início da ocorrência de precipitação pluviométrica. Arnaud-
-Santana et al. (1991) verificaram que o declínio da população de $X$. campestris pv. phaseoli em restos culturais de feijoeiro, depositados na superfície do solo, coincidiu com o período de alta precipitação, embora este fato não tenha afetado a decomposição dos resíduos. Restos culturais depositados na superfície do solo estão menos expostos a microrganismos antagonistas do que os incorporados ao solo (GILBERTSON et al., 1990). Um dos efeitos da chuva é a deposição de solo sobre os restos culturais, o que pode aumentar a exposição dos resíduos antagonistas e proporcionar um declínio na população do patógeno. Gilbertson et al. (1990) atribuíram a eliminação de $X$. campestris pv. phaseoli de restos de feijoeiro no solo, à sensibilidade desta bactéria a microrganismos antagonistas ali presentes.

Uma rápida perda de peso dos tecidos infectados de videira em função da desidratação foi verificada nos primeiros oito dias (Figura 1), seguindo-se uma lenta decomposição até a última avaliação. Isto pode explicar a sobrevivência do patógeno durante os 80 dias de avaliação, o que foi comprovado pela correlação negativa $(-0,85)$, obtida no teste de Pearson $(\mathrm{P} \leq 0,05)$, entre número de $\mathrm{UFC} \mathrm{g}^{-1}$ de tecido infectado e percentual de decomposição. Segundo Zhao et al. (2002), X. campestris pv. armoraceae e Pseudomonas syringae pv. maculicola resistentes à rifampicina sobreviveram em restos de cultura de nabo e couve na superfície do solo, durante 4 meses, não sendo mais detectados após 5 meses, quando os restos culturais estavam totalmente decompostos.

As equações: $\mathrm{UFC}=6,7-0,11$ tempo + 0,0024 tempo $^{2}-0,000018$ tempo $^{3}\left(\mathrm{R}^{2}=0,980\right)$ e DTI $=0,75+36,9$ tempo $^{1 / 2}-6,31$ tempo $+0,34$ tempo ${ }^{11 / 2}$ $\left(\mathrm{R}^{2}=0,986\right)$ foram as que melhor se ajustaram para descrever a variação na sobrevivência de $X c v 2^{\text {Rif }} \mathrm{e}$ a decomposição em tecidos infectados de videira, respectivamente (Figura 1).

Sobrevivência de $X c v 2^{\text {Rif }}$ em tecidos infectados de videira durante a compostagem

As curvas de temperatura média das pilhas de compostagem mostraram que a fase termofílica teve duração de 23 dias, sendo que, em 17 destes, foram observadas temperaturas superiores a $60^{\circ} \mathrm{C}$ (Figura 2). As altas temperaturas e a longa fase termofílica encontradas podem ser fatores pelos quais $X_{c v 2} 2^{\text {Rif }}$, já aos 10 dias, não foi detectada no material infectado. Suárez-Estrella et al. (2007) observaram que Pectobacterium carotovorum subsp. carotovorum, $P$. syringae pv. syringae, Rhizoctonia solani e Pythium ultimum foram eliminados em nove diferentes zonas de pilha de compostagem entre 48 e $120 \mathrm{~h}$, independentemente da localização. Além disto, em duas zonas que não diferiram com relação às altas 
temperaturas (43,7 e $\left.45,4^{\circ} \mathrm{C}\right)$, houve diferença nos valores de persistência dos patógenos, confirmando que a eliminação dos fitopatógenos não está associada somente às altas temperaturas alcançadas durante o processo de compostagem. Elorrieta et al. (2003) observaram que as bactérias fitopatogênicas $P$. carotovorum subsp. carotovorum, $P$. syringae pv. syringae e $X$. campestris pv. vesicatoria foram eliminadas em menos de três dias de compostagem de uma mistura de restos de cultura de pimentão, feijão e melão, e que as mesmas apresentaram baixa resistência a altas temperaturas. No presente trabalho, não se pode dizer por quanto tempo $X c v 2^{\text {Rif }}$ sobreviveu, pois a primeira amostragem foi somente aos 10 dias.

Compostos fenólicos totais foram encontrados nas pilhas de compostagem em uma concentração média de 0,013\%. Estes compostos, mesmo em baixas concentrações, são capazes de erradicar microrganismos, pois Elorrieta et al. (2003) verificaram que $0,01 \%$ de vários compostos fenólicos purificados foram suficientes para inibir o crescimento de $X$. campestris pv. vesicatoria, $P$. carotovorum subsp. carotovorum e $P$. syringae pv. syringae.

Cinco isolados bacterianos, capazes de inibir $X c v 2^{\text {Rif }}$, foram detectados em altas populações, 1,0 a 10,0 x $10^{4} \mathrm{UFC} \mathrm{g}^{-1}$ de composto. Quatro destes foram identificados utilizando o método de ésteres metil dos ácidos graxos - FAME, como: Acinetobacter calcoaceticus, Paenibacillus lentimorbus, Paenibacillus macerans e Bacillus megaterium (Tabela 2). Os gêneros Bacillus e Paenibacillus são considerados bons agentes de controle biológico de fitopatógenos. Dentre as espécies destes gêneros, $B$. megaterium, $P$. lentimorbus e $P$. macerans destacam- se por produzirem substâncias capazes de inibir microrganismos causadores de doenças de plantas (GARDENER, 2004).

De 13 isolados fúngicos obtidos do composto, três produziram metabólitos tóxicos a $X c v 2^{\text {Rif }}$, sendo as culturas identificadas como: Aspergillus fumigatus, Emericela nidulans, e E. nidulans var. acristata. Sibounnavong et al. (2008) verificaram que o composto bioativo SKP02 de E. nidulans adicionado ao meio de cultura BDA nas concentrações de 100 a $1.000 \mu \mathrm{g} \mathrm{mL}^{-1}$, inibiu o crescimento micelial e a esporulação de Fusarium oxysporum f. sp. lycopersici, após cinco dias de incubação. O grupo Aspergillus compõe-se das principais espécies de microrganismos produtores de enzimas de interesse alimentício e produtoras de micotoxinas, entretanto existem poucas informações sobre o potencial deste gênero como agente de controle de doenças de plantas. Souza et al. (2004) verificaram que isolados de A. niger, endofiticos de plantas tóxicas da Amazônia, produziam metabólitos tóxicos capazes de inibir Bacillus sp., B. subtilis, Staphylococcus aureus e Escherichia coli.

Os resultados obtidos permitem afirmar que restos de poda infectados de videira são fonte primária de inóculo de $X c v$ em parreirais situados no Submédio São Francisco, devendo ser manejados de forma correta. O processo de compostagem foi capaz de eliminar $X c v$ de tecidos de videira infectados, constituindo uma maneira viável e segura de manejar estes resíduos em parreirais, sem perigo de sobrevivência do patógeno e sem que haja a perda de uma importante fonte de matéria orgânica para a cultura.

TABELA 1- Eficácia do meio de cultura Ágar nutritivo-dextrose-extrato de levedura (NYDA) acrescido de antibióticos e fungicidas para estudos de sobrevivência de Xanthomonas campestris pv. viticola, mutante $X c v 2^{\text {Rif }}$.

\begin{tabular}{ll}
\hline Meio de cultura + antibióticos + fungicidas & Eficácia (\%) \\
\hline NYDA + rifampicina + azoxystrobim ${ }^{1}$ & $68,75^{2} \mathrm{a}$ \\
NYDA + rifampicina + ampicilina + azoxystrobim & $53,15 \mathrm{a}$ \\
NYDA + rifampicina + tiofanato metílico & $8,80 \mathrm{~b}$ \\
NYDA + rifampicina + ampicilina + tiofanato metílico & $6,84 \mathrm{~b}$ \\
\hline CV (\%) & 12,38 \\
\hline
\end{tabular}

${ }^{1}$ rifampicina $\left(0,1 \mathrm{~g} \mathrm{~L}^{-1}\right)$; azoxystrobim $\left(0,16 \mathrm{~g} \mathrm{~L}^{-1}\right)$; ampicilina $\left(0,1 \mathrm{~g} \mathrm{~L}^{-1}\right)$; tiofanato metílico $\left(0,7 \mathrm{~g} \mathrm{~L}^{-1}\right)$; ${ }^{2}$ Médias de cinco repetições. Médias seguidas pela mesma letra não diferem significativamente entre si,„pelo teste de Tukey $(\mathrm{P}<0,05)$. Dados originais transformados em $\sqrt{ } \mathrm{x}+1$, para efeito de análise. 
TABELA 2- População de espécies de bactérias antagonistas a Xanthomonas campestris pv. viticola mutante $X_{c v} 2^{\text {Rif }}$ obtidos do composto resultante da compostagem de restos de poda de videiras, aos 80 dias.

\begin{tabular}{llc}
\hline Isolado & \multicolumn{1}{c}{ Espécie } & População (x 104 UFC g ${ }^{-1}$ ) \\
\hline 1 & Acinetobacter calcoaceticus & 7,5 \\
2 & Paenibacillus lentimorbus & 1,0 \\
3 & P. macerans & 2,0 \\
4 & Não identificada & 10,0 \\
5 & Bacillus megaterium & 1,0 \\
\hline
\end{tabular}

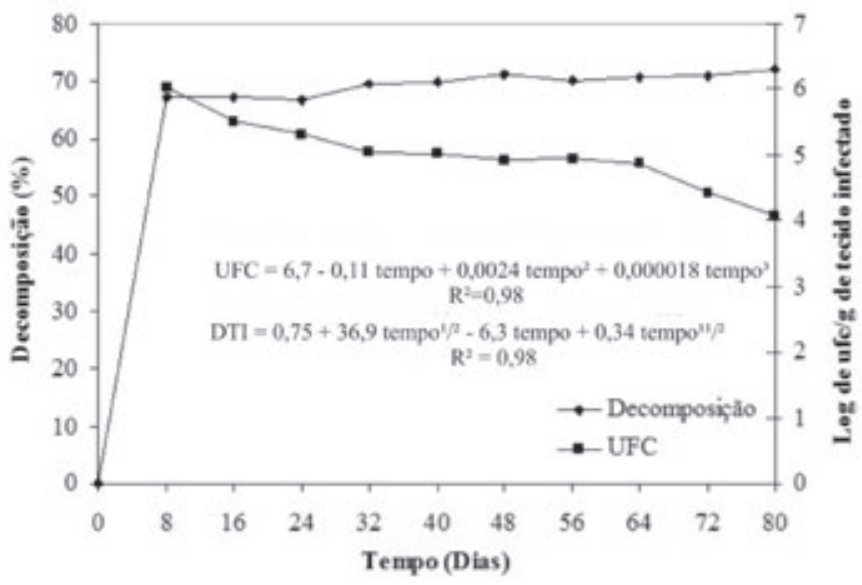

FIGURA 1- Sobrevivência de Xanthomonas campestris pv. viticola, mutante $X c v 2^{\text {Rif }}$ e percentual de decomposição de tecidos infectados de videira depositados na superfície do solo em microparcelas.

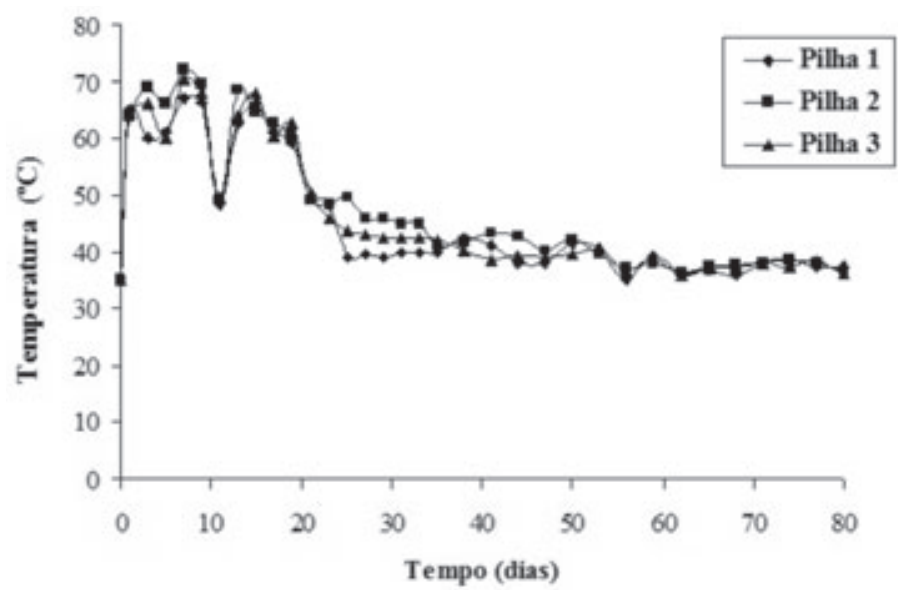

FIGURA 2- Curva de temperatura média $\left({ }^{\circ} \mathrm{C}\right)$ das pilhas de compostagem de restos de poda de videira. 


\section{CONCLUSÕES}

1- Xanthomonas campestris pv. viticola sobrevive em altas populações, por pelo menos 80 dias, em tecidos infectados de videira na superfície do solo.

2- O processo de compostagem de restos de poda elimina $X$. campestris pv. viticola de tecidos infectados de videira em 10 dias.

\section{AGRADECIMENTOS}

Ao Dr. Itamar S. de Melo, da Embrapa Meio Ambiente, pela identificação dos isolados bacterianos; à Dra. Cristina Motta, da Universidade Federal de Pernambuco, pela identificação dos isolados fúngicos; ao $\mathrm{CNPq}$, pela concessão das bolsas de Doutorado e Produtividade em Pesquisa, e do apoio Financeiro Proc. 472.555/2009-0.

\section{REFERÊNCIAS}

ARAÚJO, J.S.P. Perfil epidemiológico e subsídios para o controle de Xanthomonas campestris pv. viticola (Nayudu) Dye, agente do cancro bacteriano da videira (Vitis vinifera) no Brasil. 2001. 121f. Tese (Doutorado em Fitotecnia) Universidade Federal Rural do Rio de Janeiro., Seropédica, 2001.

ARNAUD-SANTANA, E.; PENA-MATOS, E.; COYNE, D.P.; VIDAVER, A.K. Longevity of Xanthomonas campestris pv. phaseoli in naturally infested dry bean (Phaseolus vulgaris) debris. Plant Disease, Saint Paul, v.75, n.9, p.952-953, 1991.

BARAK, J.D.; KOIKE, S.T.; GILBERTSON, R.L. The role of crop debris and weeds in the epidemiology of bacterial leaf spot of lettuce in California. Plant Disease, Saint Paul, v.85, n.2, p.169-178, 2001.

ELORRIETA, M.A.; SUÁREZ-ESTRELLA, M.J.; LÓPEZ, M.C.; VARGASGARCÍA, J.; MORENO, J. Survival of phytopathogenic bacteria during waste composting. Agriculture, Ecosystems and Environment, Amsterdam, v.96, n.1, p.141-146, 2003.

FATMI, M.; SCHAAD, W.N. Survival of Clavibacter michiganensis ssp. michiganensis in infected tomato stems under natural field conditions in California, Ohio and Morocco. Plant Pathology, Oxford, v.51, n.1, p.149-154, 2002.
GARDENER, M.B.B. Ecology of Bacillus and Paenibacillus spp. in agricultural systems. Phytopathology, Saint Paul, v.94, n.11, p.12521258, 2004.

GILBERTSON, R.L. RAND, R.E.; HAGEDORN, D.J. Survival of Xanthomonas campestris pv. phaseoli and pectolytic strans of $X$. campestris in bean debris. Plant Disease, Saint Paul, v.74, n.4, p.322-327, 1990.

HOITINK, H.A.J; FAHY, P.C. Basis for the control of soil-borne plant pathogens with composts. Annual Review of Phytopathology, Palo Alto, v.24, n.1, p.93-114, 1986.

JONES, J.B.; POHRONEZNY, K.L.; STALL, R.E. Survival of Xanthomonas campestris pv. vesicatoria in Florida on tomato crop residue, weeds, seeds, and volunteer tomato plants. Phytopathology, Saint Paul, v.76, n.4, p.430-434, 1986.

LIMA, M.F.; MOREIRA, W.A. Doenças causadas por bactérias. In: LIMA, M.F.; MOREIRA, W.A. (Ed.). Uva de mesa: fitossanidade. Brasília: Embrapa Informação Tecnológica, 2002. p.27-34.

MALAVOLTA JÚNIOR, V.A.; BERIAM, L.O.S.; ALMEIDA, I.M.G.; RODRIGUES NETO, J.; ROBBS, C.F. Bactérias fitopatogênicas assinaladas no Brasil: uma atualização. Summa Phytopathologica, Jaboticabal, v.34, p.9-88, 2008. Suplemento.

MALAVOLTA JÚNIOR V.A.; ALMEIDA, I.M.G.; SUGIMORI, M.H.; RIBEIRO, I.J.A.; RODRIGUES NETO, J. Ocorrência de Xanthomonas campestris pv. viticola em videira no Brasil. Summa Phytopathologica, Botucatu, v.25, n.3 p.262-264, 1999.

MARIANO, R.L.R.; GOMES, A.M.A.; ASSIS, S.M.P.; SILVEIRA, E.B. Mecanismos de ação de bactérias promotoras de crescimento de plantas. In: MARIANO, R.L.R.; SILVEIRA, E.B. Manual de práticas em fitobacteriologia. Recife: UFRPE, 2005a. p. 143-158.

MARIANO, R.L.R.; SILVEIRA, E.B.; ASSIS, S.M.P.; GOMES, A.M.A. Identificação de bactérias fitopatogênicas. In: MARIANO, R.L.R.; SILVEIRA, E.B. Manual de práticas em fitobacteriologia. Recife: UFRPE, 2005b. p. 67-111. 
NASCIMENTO, A.R.P.; MARIANO, R.L.R.; GAMA, M.A.S. Métodos de preservação e crescimento de Xanthomonas campestris pv. viticola em meio de cultura variando temperatura, $\mathrm{pH}$ e concentração de $\mathrm{NaCl}$. Fitopatologia Brasileira, Brasília, v.30, n.6, p.650-654, 2005.

PEIXOTO, A.R.; MARIANO, R.L.R.; MOREIRA, J.O.T.; VIANA, I.O. Hospedeiros alternativos de Xanthomonas campestris pv. viticola. Fitopatologia Brasileira, Brasília, v.32, n.2, p.161-164, 2007.

PEIXOTO, A.R.; MARIANO, R.L.R.; VIANA, I.O. Meio semi-seletivo para isolamento de Xanthomonas campestris pv. viticola. Ciência Rural, Santa Maria, v.36, n.4, p.1317-1320, 2006.

REICHER, F.; SIERAKOWSKI, M.R.; CORREA, J.B.C. Determinação espectro-fotométrica de taninos pelo reativo, fosfotúngstico-fosfomolíbdico. Arquivos de Biologia e Tecnologia, Curitiba, v.24, n.4, p.401-411, 1981.

RODRIGUES NETO, J.; DESTÉFANO, S.A.L.; RODRIGUES, L.M.R.; PELLOSO, D.S.; OLIVEIRA JÚNIOR, L.C. Grapevine bacterial canker in the State of São Paulo, Brazil: detection and eradication. Tropical Plant Pathology, Brasília, v.36, n.1, p.4244, 2011.

SIBOUNNAVONG, D.C.; CYNTHIA, D.C.; KANOKMEDHAKUL, S.; SOYTONG, K. The new antagonistic fungus, Emericella nidulans strain EN against Fusarium wilt of tomato. Journal of Agricultural Technology, Bangkok, v.4, n.1, p.8999, 2008.
SOUZA, A.Q.L. de; SOUZA, A.D.L. de; ASTOLFI FILHO, S.; BELÉM PINHEIRO, M.L.; SARQUIS, M.I.M.; PEREIRA, J.O. Atividade antimicrobiana de fungos endofíticos isolados de plantas tóxicas da amazônia: Palicourea longiflora (Aubl.) Rich e Strychnos cogens Bentham. Acta Amazonica, Manaus, v.34, n.2, p.185-195, 2004.

SUÁREZ-ESTRELLA, F.; VARGAS-GARCÍA, M.C.; LÓPEZ, M.J.; MORENO, J. Effect of horticultural waste composting on infected plant residues with pathogenic bacteria and fungi: Integrated and localized sanitation. Waste Management, Oxford, v.27, n.9, p.886-892, 2007.

TOUSSAINT, V.; MORRIS, C.E.; CARISSE, O. A new semi-selective medium for Xanthomonas campestris pv. vitians, the causal agent of bacterial leaf spot of lettuce. Plant Disease, Saint Paul, v.85, n.2, p.131-136, 2001.

TUITE, J. Plant pathological methods: fungi and bacteria. Minneapolis: Burgess, 1969. 239p.

WYDRA, K.; GOPAL, K.C.; MAVRIDIS, A.; SIKIROU, R. A diagnostic medium for the semiselective isolation and enumeration of Xanthomonas axonopodis pv. vignicola. European Journal of Plant Pathology, Dordrecht, v.110, n.10, p.9911001, 2004.

ZHAO, Y.; DAMICONE, J.P.; BENDER, C.L. Detection, survival, and sources of inoculum for bacterial diseases of leafy crucifers in Oklahoma. Plant Disease, Saint Paul, v.86, n.8, p.883-888, 2002. 